\title{
The Effect of Health Education Based on the Health Belief Model about Pap Smear Test on Women in Rural District Indonesia
}

\author{
Ernawati $^{1}$, Dina Oktaviana ${ }^{1}$, Mantasia $^{1}$, Rezky Aulia Yusuf $^{2}$, Sumarmi $^{1}$ \\ ${ }^{1}$ Nursing College, STIKes Tanawali Takalar, ${ }^{2}$ Faculty of Public Health, Universitas Muslim Indonesia
}

\begin{abstract}
Background: The aim of this study was to evaluate the effectiveness of educational interventions based on Health Belief Models (HBM) on the adoption of cervical cancer screening and prevention behaviours in Indonesian women in a rural district.

Method: This is a quasi-experimental study with pre-test and post-test design. The convenience sampling was used and a total of 100 women participated in this study. One hour educational intervention based on a health belief model including lectures, question and answer, group discussions and booklets on cervical cancer and cervical cancer screening provided to participants. The content of the session included basic information regarding cervical cancer facts, important early detection, recommended screening method, guidelines for Pap smear screening and the role of pap smears in early diagnosis of cervical cancer. As well as, pamphlets distributed to participants. Post-test test hold within six months after the end of the intervention.
\end{abstract}

Results: The findings showed that the mean difference of the scores before and after health educational intervention about Pap smear and cervical cancer for all constructs (except; perceived susceptibility and severity were no changes) has increased significantly with P-value $<0.001$.

Conclusion: Providing rigorous information to women about the risk of cervical cancer the benefits of early detection of cervical cancer and having regular Pap smear tests are crucial to increase the intention to undergo cervical cancer screening among women in a rural area.

Keywords: Health education, health beliefs model, Pap smear.

\section{Introduction}

Cervical cancer is the main cancer in women, and the leading cause of death in women around the world including in Indonesia ${ }^{1,2}$. According to WHO data in 2012, in Indonesia cervical cancer is the second leading cause of death on women with cancer, with an incidence

\section{Corresponding Author}

Sumarmi

Nursing College, STIKes Tanawali Takalar

Address: Jalan. Pangeran Diponegoro. No 65, Kab.

Takalar, South Sulawesi, Indonesia

e-mail:mhimy.arief@gmail.com of 20,928 cases and 9,498 deaths, cases per 100,000 women. In addition, the burden of cervical cancer is very high $(>80 \%)$ in developing countries ${ }^{3}$.

Early detection of cervical cancer can prevent or delay the progression of cervical abnormalities to become invasive ${ }^{4}$. Pap smear screening is effective in reducing the incidence and mortality of cervical cancer cases $^{5-7}$. In fact, when cervical cancer is found early, it is possible to treat it. Starting June 2014, the Indonesian government has offered free Pap smear screening to married women over the age of 30 to reduce the incidence of cervical cancer.In Indonesia, women with low socioeconomic status generally seek healthcare only when they experience the symptoms, and it is strenuous to treat the advanced stage of cervical cancer ${ }^{8}$. 
According to the health belief model (HBM), women are quicker to seek health services if their perceptions of vulnerability and seriousness related to certain health conditions are high, barriers to carrying out such behavior are low, and the benefits of engaging in health behaviors are very important ${ }^{9} .10$ Similarly, health beliefs about cervical cancer screening have been shown to be important in determining behaviors associated with cancer prevention ${ }^{10}$.

Knowledge has an important role in influencing women's decisions to undergo cervical cancer screening. Research shows that having sufficient knowledge of cervical cancer and a screening program increases the acceptance and use of available screening services. Designing efficient educational programs by selecting suitable and influential theories or models for behavior change. Health education is the main basis for all cancer prevention interventions in women. The aim of this study was to evaluate the effectiveness of educational interventions based on health belief models on screening behavior and prevention of cervical cancer in women in Indonesia.

\section{Method}

A quasi-experimental study with pre-test and posttest designs was used to evaluate the effectiveness of educational interventions based on a health belief model in preventing cervical cancer among Indonesian women in Takalar district. Post- test hold within six months after the end of the intervention. Convenience sampling was applied to recruit a sufficiently representative sample of the target population in Takalar District, a rural area with an estimate of around 66,000 women (Central Bureau of Statistics, Takalar District, 2012).

The inclusion criteria for study participants were married women, aged $\geq 18$ years, able to communicate using Indonesian (national language), regardless of whether they could read or not. The exclusion criteria were women with a history of cervical cancer or hysterectomy. G*Power version 3.1.9.2 was used to perform sample size assuming $\alpha=0.05$, power level $=$ 0.8 , and an effect size of 0.36 . The minimum sample size is estimated to be 59 . Given the $10 \%$ reduction rate, a total of 70 participants will be recruited into this study.

Measurements: All variables were measured using a questionnaire. Health Beliefs Model Scale for Cervical Cancer and Pap The Smear test (HBMSCCPS) was used to assess the health confidence of cervical cancer screening ${ }^{11}$. The scale was modified from the Champion Health Beliefs Model (CHBM) scale ${ }^{12}$ and the HBMSCCPS consisted of 35 items (5 subscales) with a five-point Likert scale from strongly disagree (score 1 ) to strongly agree (score 5). HBMSCCPS retest tests ranged from 0.79 to 0.87 and Cronbach's alpha ranged from 0.62 to $0.86^{11}$. The questionnaire consisted with five subscales; "benefits of pap smear test" consisted 8 questions, "barriers to pap smear test" for 14 questions, "perceived seriousness of cervical cancer" for 7 questions, "susceptibility to cervical cancer" for 3 questions, and "health motivation" consisted of 3 questions. The mean of the item-Content Validity Index (I-CVI) was 0.99 and the mean -CVI score was 0.97 for Indonesian questionnaire. As well as, the internal consistency of HBMSCCPS with Cronbach's alpha = 0.69 for the total score.

Data Collection Procedure: The principal investigator (PI) and one research assistant collected and analyzed the data. After obtaining IRB approval from Muhammadiyah Jogyakarta University, PI will seek permission from the head of the community health center, and also visit community health cadres in each district to identify potential subjects that meet all the inclusion criteria. Women who met the inclusion criteria and agreed to participate were provided with informed consent to be read and signed, and then asked to complete a pre-test questionnaire, including demographic data, intention to take cervical cancer screening, Health Belief Model Scale for Cervical Cancer and Pap Smear Test.

One-hour educational intervention based on a health belief model including basic information regarding cervical cancer facts (e.g. epidemiology, signs/symptoms and risk factors for cervical cancer development), important early detection, recommended screening method, guidelines for Pap smear screening and the role of Pap smears in early diagnosis of cervical cancer. Pamphlets were also be distributed to all participants. The post-test will measure after the end of the intervention.

Statistical Analysis: The analysis was carried out using SPSS version 26.0. Descriptive statistics of proportion used to analyze the demographics data and for Health Model Belief data used a paired sample t-test to provide further description and evaluation of the intervention with a statistical significance of 0.05 . 


\section{Result}

Table 1. The Demographic characteristics of the respondents in Takalar District

\begin{tabular}{|c|c|}
\hline \multirow[b]{2}{*}{ Variables } & Group \\
\hline & $\begin{array}{c}\text { Intervention } \\
n=100(\%)\end{array}$ \\
\hline \multicolumn{2}{|l|}{ Marital Status } \\
\hline Married & 92 \\
\hline Divorced/widow & 8 \\
\hline \multicolumn{2}{|l|}{ Age } \\
\hline$<20$ & 7 \\
\hline $21-30$ & 15 \\
\hline $31-40$ & 36 \\
\hline$>41$ & 42 \\
\hline \multicolumn{2}{|l|}{ Education } \\
\hline No & 7 \\
\hline Elementary & 25 \\
\hline Junior high school & 27 \\
\hline Senior high school & 30 \\
\hline Bachelor & 11 \\
\hline \multicolumn{2}{|l|}{ Tribes } \\
\hline Makassar & 97 \\
\hline Buginese & 3 \\
\hline Others & 0 \\
\hline \multicolumn{2}{|l|}{ Occupational } \\
\hline Not working/housewife & 76 \\
\hline Civil servant & 1 \\
\hline Entrepreneur & 4 \\
\hline Officer & 1 \\
\hline Others & 18 \\
\hline \multicolumn{2}{|l|}{ Salary } \\
\hline$<1.5$ million & 74 \\
\hline 1.5-2.5 million & 10 \\
\hline$>2.5-3.5$ million & 5 \\
\hline$>3.5$ million & 11 \\
\hline \multicolumn{2}{|l|}{ History of Partum } \\
\hline No & 14 \\
\hline Yes & 86 \\
\hline
\end{tabular}

\begin{tabular}{|c|c|}
\hline \multirow[b]{2}{*}{ Variables } & Group \\
\hline & $\begin{array}{c}\text { Intervention } \\
\mathrm{n}=100(\%)\end{array}$ \\
\hline \multicolumn{2}{|l|}{ Religion } \\
\hline Islam & 99 \\
\hline Kristen & 1 \\
\hline Hindu & 1 \\
\hline \multicolumn{2}{|c|}{ Received Cervical Cancer Information } \\
\hline No & 45 \\
\hline Yes & 55 \\
\hline \multicolumn{2}{|c|}{ Received Pap smear Information } \\
\hline No & 60 \\
\hline Yes & 40 \\
\hline \multicolumn{2}{|l|}{ Did Pap Smear } \\
\hline Never & 91 \\
\hline Frequently & 8 \\
\hline Every $1-3$ years & 1 \\
\hline Rarely & 0 \\
\hline \multicolumn{2}{|c|}{ Family History of Cervical Cancer } \\
\hline No & 97 \\
\hline Yes & 3 \\
\hline \multicolumn{2}{|c|}{ Friends History of Cervical Cancer } \\
\hline No & 98 \\
\hline Yes & 2 \\
\hline
\end{tabular}

Source: Primary Data, 2020

The table 1 showed that the characteristic of the total 100 respondents participated in this study. The results showed that the average age of the participants was $39.66 \pm 1.25$. The majority of the participants were Muslims (99\%), Makassarnese (97\%),married (92\%), worked as housewife (76\%), history of partum (86\%) and income $<1.5$ million per month (74\%).In addition, $60 \%$ of total participants had received cervical cancer and Pap smear information. Most of participants reported never did Pap smear (91\%), as well as most of them did not have family and friends with the history of cervical cancer respectively $97-98 \%$. 
Table 2. The mean \pm SD of scores of construct of Health belief model in women before and after Intervention

\begin{tabular}{|l|c|c|c|}
\hline \multirow{2}{*}{ Variables } & \multicolumn{3}{|c|}{ Intervention } \\
\cline { 2 - 3 } & Pre & Post & \multirow{2}{*}{ P value } \\
\cline { 2 - 4 } & Mean \pm SD & $<.2 \pm 0.79$ & $<0.001$ \\
\hline Benefits of Papsmear test & $3.8 \pm 0.78$ & $3.4 \pm 0.81$ & 0.001 \\
\hline Barriers to Papsmear & $3.1 \pm 0.63$ & $2.9 \pm 0.72$ & 0.333 \\
\hline Perceived Seriousnessof Cervical Cancer & $2.9 \pm 0.76$ & $2.0 \pm 0.83$ & 0.361 \\
\hline Susceptibility to Cervical Cancer & $2.0 \pm 0.81$ & $4.2 \pm 0.90$ & $<0.001$ \\
\hline Health Motivation & $3.9 \pm 0.93$ & & \multirow{2}{*}{$<$} \\
\hline
\end{tabular}

Source: Primary Data, 2020

Table 2 reported that the mean scores of the construct of the benefits of Pap smear test in pre-test were $3.8 \pm 0.78$ and after the intervention increase to $4.2 \pm 0.79$ with the statistically significant $(P<0.001)$. Related on the construct of barriers to Pap smear showed the mean scores before intervention were $3.1 \pm 0.63$ and $3.4 \pm 0.81$ after interventions with the $p$ value 0.001 . In addition, the construct of perceived seriousness of cervical cancer and susceptibility to cervical cancer revealed no change in the mean scores before and after intervention. While, related the construct of health motivation showed the mean scores increased from $3.9 \pm 0.93$ to $4.2 \pm 0.90$ respectively before and after intervention with $p$ value $<0.001$.

Table 3. The Mean Difference Before and After Intervention

\begin{tabular}{|l|c|}
\hline Variables & Mean Difference \\
\hline Benefits of Papsmear test & 0.4 \\
\hline Barriers to Papsmear & 0.3 \\
\hline Health Motivation & 0.3 \\
\hline
\end{tabular}

Source: Primary Data, 2020

Table 3 showed the mean difference before and after intervention for the construct of benefits of Papsmear test were increased 0.4, while the construct of barriers to Papsmear and health motivation were increased 0.3 .

\section{Discussion}

The major focus of this study is to investigate the effect of health educational intervention based on health belief model scale in improving the health confidence of cervical cancer screening among adult women in Takalar, a rural district in South Sulawesi Indonesia.
Of total 100 respondents received 40-60 minutes health educational intervention.

This study revealed that there was a significant increase of the confidence on participants based on the perceived benefits of Pap smear test subscales. This findings is similar with the result of another study among 70 women in Iran, this study found that women were more sensible of the advantages from doing pap smear after the education ${ }^{13}$. Further, this finding were also proved by other studies ${ }^{14,15}$. The highlight on perceived benefits has been emphasized in some studies about the persuasion of adults' women to undertake the Pap smear test ${ }^{14,16}$. Considering to the impact of knowledge on practice, lack of knowledge about the advantages and the functions of the pap smear might be as the caused for poor practice of pap smear. Consistent with our results, another study also known the lack of knowledge as one of the primary reasons of low participation on the cervical cancer screening test ${ }^{13}$.After the intervention of health education, the level of knowledge was improved notably that was emphasized on the effect of the health education on participants' knowledge. This study findings validated by other similar studies ${ }^{13}$. Another study has also confirmed the impact of educational intervention on increasing women's knowledge and participation in cervical cancer screening program ${ }^{15}$. However, there was appositive relationships for designing educational interventions for changing the knowledge levels and women beliefs ${ }^{17}$.

Furthermore, this study also found that there was a significant decreased of the perceived barriers to undergo Pap smear test among the women after the intervention. Designing and implementing educational program based on health belief model can promote women's 
awareness and reduce their perceived barriers and as well as enhance their practice regarding Pap smear test ${ }^{15,18}$.This findings may refers to the effectiveness of educational intervention based on the Health Belief Model that has caused the women in the intervention group able to overcome the barriers ${ }^{15}$. This findings is contrast with other studies which reported that educational intervention increased the perceived barriers in intervention group ${ }^{13,14}$. Psychological barriers for instance fear and embarrassment have been the most crucial barriers among women.

With regards to perceived susceptibility and severity in intervention group showed no effect on the confidence of taking cervical cancer screening program. It might be due to insufficient intervention time for influencing the attitudes of the adult's women ${ }^{13}$. In contrast with other study that reported the increasing in the mean scores after receiving education about cervical cancer ${ }^{14,16}$.

Moreover, regarding the health motivation subscales showed that there was a significant increased on women motivation to do Pap smear test. This result also supports by the study among 106 women in Iran that showed the mean difference of the scores before and immediately after educational intervention was significant higher than score before intervention ${ }^{19}$.

This study has some limitations; the sample limited to women who referred to the healthcare centers and only include small sample group. Further, it is suggested that future research should recruit participants from variety groups of women, increasing the total number of participants would also allow for a more robust results and analysis. As well as, this research had pre- and postintervention measurements at two times, which showed only the short-term effects of the health educational intervention.

\section{Conclusion}

Generally, the results of this research suggested that health education based on Health Belief Model guide to encourage women to do Pap smear test. By considering the advantages of taking Pap smear as a helpful screening tools, health educational intervention based on Health Belief Model is highly advocated in healthcare centers.

Acknowledgements: The authors would like to thank to all participants and the Ministry of Education of Republic Indonesia (DIKTI) for the funding (Contract number: 231/SP2H/LT/DRPM/2019).
Conflict of Interest: None declared.

Ethical Clearance: This research was approved by the ethical committee of Muhammadiyah Jogyakarta University. Before participation on the research process, all participants signed an informed consent and all the interests of all participants are secured.

\section{References}

1. Domingo EJ, Noviani R, Noor $M R$, et al. Epidemiology and prevention of cervical cancer in Indonesia, Malaysia, the Philippines, Thailand and Vietnam. Vaccine. 2008;26 Suppl 12:M71-79.

2. Ferlay J, Soerjomataram I, Dikshit R, et al. Cancer incidence and mortality worldwide: sources, method and major patterns in GLOBOCAN 2012. Int J Cancer. 2015;136(5):E359-386.

3. Arbyn M, Castellsagué X, Sanjosé $S$, et al. Worldwide burden of cervical cancer in 2008 . Annals of oncology : official journal of the European Society for Medical Oncology/ESMO. 2011;22:2675-2686.

4. Saslow D, Solomon D, Lawson HW, et al. American Cancer Society, American Society for Colposcopy and Cervical Pathology, and American Society for Clinical Pathology screening guidelines for the prevention and early detection of cervical cancer. CA Cancer J Clin. 2012;62(3):147-172.

5. Gakidou E, Nordhagen S, Obermeyer Z. Coverage of cervical cancer screening in 57 countries: low average levels and large inequalities. PLoS Med. 2008;5(6):e132.

6. Gümüş AB. Relationships between early diagnosis attitudes in cervical cancer of women and levels of self-esteem, body perception and hopelessness. Nobel Medicus. 2011;7:46-52.

7. Peto J, Gilham C, Fletcher O, Matthews FE. The cervicalcancerepidemic that screening has prevented in the UK. The Lancet. 2004;364(9430):249-256.

8. Aziz MF. Gynecological cancer in Indonesia. J Gynecol Oncol. 2009;20(1):8-10.

9. Jones CL, Jensen JD, Scherr CL, Brown NR, Christy K, Weaver J. The Health Belief Model as an explanatory framework in communication research: exploring parallel, serial, and moderated mediation. Health Commun. 2015;30(6):566-576.

10. Phipps E, Cohen M, Sorn R, Braitman L. A pilot study of cancer knowledge and screening 
behaviours of Vietnamese Cambodian women. Health care for women international. 1999;20:195207.

11. Guvenc G, Akyuz A, Açikel CH. Health Belief Model Scale for Cervical Cancer and Pap Smear Test: psychometric testing. J Adv Nurs. 2011;67(2):428-437.

12. Champion, V. L. Instrument refinement for breast cancer screening behaviors, (1993).

13. Pirzadeh A, Mazaheri MA. The Effect of Education on Women's Practice Based on the Health Belief Model About Pap Smear Test. Int J Prev Med. 2012;3(8):585-590.

14. Ahmed S, Esa A, MohamedEl-zayat O. Health Belief Model-based educational program about cervical cancer prevention on women knowledge and beliefs. Egyptian Nursing Journal. 2018;15(1):39-49.

15. Khademolhosseini F, Noroozi A, Tahmasebi R. The Effect of Health Belief Model-Based Education through Telegram Instant Messaging Services on
Pap smear performance. Asian Pac J Cancer Prev. 2017;18(8):2221-2226.

16. Akbari F, SHEYKHZADEH E, Pourreza A, Tavafian S. Barriers and facilitating factors for cervical cancer screening: A qualitative study from Iran. 2010.

17. Karimy M, Azarpira H, Araban M. Using Health Belief Model Constructs to Examine Differences in Adherence to Pap Test Recommendations among Iranian Women. Asian Pac J Cancer Prev. 2017;18(5):1389-1394.

18. Tahmasebi R, Hosseini F, Noroozi A. The effect of education based on the health belief model on women's practice about pap smear test. 2016;21:8092.

19. Suanda J, Suanda J, Cawley D, Domegan C, Brenner M, Rowan N. A Review of the Perceived Barriers within the Health Belief Model on Pap Smear Screening as a Cervical Cancer Prevention Measure. Journal of Applied Science Research. 2013;3. 